\title{
Preparation and Monitoring of Lead Acetate Containing Drinking Water Solutions for Toxicity Studies
}

William R. Blair

Kenneth $L$. Jewett

Francis W. Wang

Susannah B. Schiller

U.S. DEPARTMENT OF COMMERCE

Technology Administration

National Institute of Standards

and Technology

Materials Science and Engineering Laboratory

Polymers Division

Gaithersburg, MD 20899

Prepared for:

The University of Maryland at Baltimore

660 West Redwood Street

Baltimore, Maryland 21201 



\section{Preparation and Monitoring of \\ Lead Acetate Containing \\ Drinking Water Solutions for \\ Toxicity Studies}

William R. Blair

Kenneth L. Jewett

Francis W. Wang

Susannah B. Schiller

U.S. DEPARTMENT OF COMMERCE

Technology Administration

National Institute of Standards

and Technology

Materials Science and Engineering Laboratory

Polymers Division

Gaithersburg, MD 20899

Prepared for:

The University of Maryland at Baltimore 660 West Redwood Street

Baltimore, Maryland 21201

May 1994

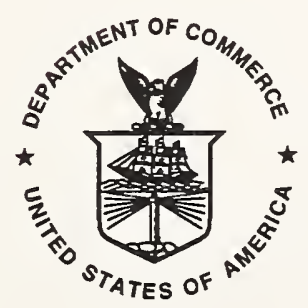

U.S. DEPARTMENT OF COMMERCE

Ronald H. Brown, Secretary

TECHNOLOGY ADMINISTRATION

Mary L. Good, Under Secretary for Technology

NATIONAL INSTITUTE OF STANDARDS

AND TECHNOLOGY

Aratl Prabhakar, Dlrector 

TABLE OF CONTENTS

1.0 Introduction . . . . . . . . . . . . . . . 1

1.1 Objective . . . . . . . . . . . . . . . 1

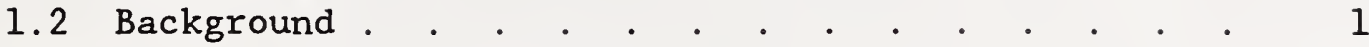

2.0 Experimental . . . . . . . . . . . . . . 2

2.1 Labware and Bottle Cleaning . . . . . . . . 2

2.2 Preparation of 20,000 PPM Concentrated Lead Solution 2

2.3 Dosing Solution Preparation . . . . . . . . 4

2.4 Solution Monitoring by FAAS . . . . . . . . 5

3.0 Discussion . . . . . . . . . . . . . . . . 5

3.1 Solutions of Lead Acetate . . . . . . . . . 5

3.2 Rat Drinking Water Solutions . . . . . . . . 7

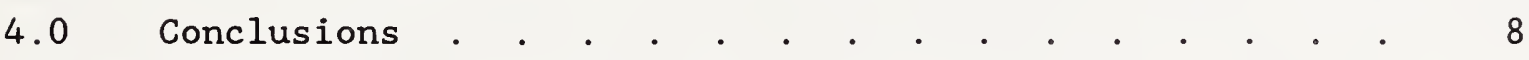

5.0 References . . . . . . . . . . . . . . . . . . . 9

5.1 Acknowledgements . . . . . . . . . . . . . . . . 59

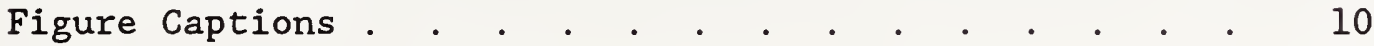

Appendix . . . . . . . . . . . . . . . 11 



\subsection{INTRODUCTION}

\subsection{Objective}

The objectives of the work described in this report were to design and implement a drinking water solution preparation and monitoring program as part of a collaborative interaction with the University of Maryland at Baltimore (UMAB) and the University of Maryland at Catonsville, for an animal study of lead toxicity. Drinking water solutions containing lead at concentrations of 50,250 and 1,000 parts per million ( $\mathrm{ppm}, \mathrm{mg} / \mathrm{L}$ ) would be required for approximately two and one-half years during which the molecular mechanisms and tumorigenic response of low-dose lead exposure in a group of 370 male Fischer344 rats were examined. The drinking water program had to address questions of solution preparation, transportation, storage, stability and monitoring of solution lead concentration. An additional responsibility was to provide trace metal measurement support to the project by the determination of lead concentrations in tissues from animals consuming the lead containing drinking water. Drinking water solutions were prepared from lead acetate compound. The amount of compound used was calculated to produce a lead solution with the concentration expressed as ppm lead, not ppm of lead acetate compound.

\subsection{Background}

The large number of animals involved and the lengthy duration of lead exposure in this experiment presented requirements for a large volume of lead-

containing drinking water. At the initiation of the experiment, volumes of 60 to 80 liters of lead-containing solution at each of the three dose levels were required, a total of 180 to 240 liters per month. To reduce the volume of drinking water solution shipped from NIST to UMAB, an evaluation was made on the feasibility of preparing highly concentrated lead solutions (20,000 ppm) at NIST and shipping them to UMAB for dilution just prior to use. The goal was to provide a stable, concentrated lead solution that would reproducibly provide, upon dilution, twenty liter volumes of drinking water with lead concentrations of 50,250 and $1,000 \mathrm{ppm}$, accurate to within 5 percent of the intended concentrations.

Accordingly, the first experiments undertaken for this program (1) determined the stability of aqueous inorganic lead solutions. An understanding of potential solution/container interactions such as irreversible adsorption of metal species to container walls, solubility of metal compounds in aqueous solution and the need for long term molecular stability of the solute species were critical aspects of this project. Prior experience with preparation, storage, and monitoring of dilute, aqueous metal and organometal solutions (2) provided the necessary understanding to undertake preparation of stable lead containing drinking water solutions.

Polycarbonate containers were chosen as the least likely to adsorb lead from aqueous solution. Solutions of lead acetate in deionized water, at concentrations of $20,000,1,000,250$ and $50 \mathrm{ppm}$, buffered with acetic acid and adjusted to $\mathrm{pH} \mathrm{4.5,} \mathrm{were} \mathrm{monitored} \mathrm{for} \mathrm{concentration} \mathrm{stability.} \mathrm{Lead}$ concentrations in the solutions were determined by atomic absorption spectrophotometry. Both graphite furnace (GFAAS) and flame atomization (FAAS) 
atomic absorption techniques were employed for solution concentration monitoring, with the vast majority of determinations made using FAAS. Monitoring periods varied from 30 days to 5 months in length, depending on the concentration of the lead solution being examined. After five months of room temperature $\left(\approx 20^{\circ} \mathrm{C}\right)$ storage in the dark, a concentrated lead solution, with an initial concentration determined to be $20,000 \mathrm{ppm}$ with a standard deviation of $300 \mathrm{ppm}$, experienced a 5 percent loss in concentration to 19,000 ppm with a standard deviation of $100 \mathrm{ppm}$.

The stability of lead solutions at nominally 50, 250 and 1,000 ppm concentration levels was monitored for more than 11 weeks. The average lead concentration determined at the end of the stability study ranged from 99.7 to 101.6 percent of the average concentration determined at the start of the 11 week monitoring period.

Preparation of 20-liter volumes of dosing solutions by dilution of $50 \mathrm{~mL}, 250$ $\mathrm{mL}$ and $1,000 \mathrm{~mL}$ volumes of $20,000 \mathrm{ppm}$ concentrated lead solution was readily accomplished with an accuracy of better than \pm 5 percent of the target concentration. Lead concentration determinations made on 20-liter volumes of 50,250 and $1,000 \mathrm{ppm}$ solutions approximately 30 days after the dilutions were performed revealed solution concentrations that ranged from 100.6 to 103.7 percent of their target values.

The requirements for accurate lead solution concentrations during the animal study of lead toxicity were established to be within 5 percent of the target concentration. As the above concentration monitoring experiments reveal, this criteria could be met or exceeded by the protocols developed.

\subsection{EXPERIMENTAL}

\subsection{Labware and Bottle Cleaning}

Prior to use in the weighing and subsequent dilution of lead acetate solutions, all spatulas, beakers and carboys that would come into contact with the lead acetate compound or solutions were cleaned to remove any preexisting trace metal contamination. All items were given a soap and hot water washing, rinsed in deionized water and leached with $5 \%$ aqueous nitric acid at $40{ }^{\circ} \mathrm{C}$ for a minimum of 48 hours. After 4 to 5 rinses in deionized water, the above labware was considered ready for use. The lead concentration of the deionized rinse water was determined by GFAAS. No lead could be determined in the deionized water. The deionized water lead concentration was below the level

detectable by the GFAAS instrument, which was 0.6 parts per billion $(0.6 \mu \mathrm{g} / \mathrm{L})$ when the furnace was equipped with a conventional pyrolytically coated graphite tube.

\subsection{Preparation of 20,000 ppm Lead Concentrate Solutions}

Aqueous lead acetate solutions of 20 liter volumes, with a lead concentration of approximately $20,000 \mathrm{ppm}$ were prepared as follows. A 20 liter 
polycarbonate carboy (Carboy 非322, Nalge Co., Rochester, NY) ${ }^{1}$ with polypropylene spigot and cap served as the solution reservoir. Seventeen liters of deionized water (Culligan Aqua Suma Reagent Water System, McNew Culligan Inc., Edgewater, MD) were measured into the carboy using a one liter graduated cylinder. Lead acetate compound, $732.3 \mathrm{~g}$, (Fluka Chemical Corp., Ronkonkoma, NY) was weighed into a tared pyrex glass beaker and then slowly added to the carboy. During the addition of the lead acetate and for several hours afterward, the carboy contents were stirred with a heavy duty magnetic stirrer (Maxi-Stirrer Type 25500, Barnstead/Thermolyne Corp., Dubuque, IA) and a teflon or pyrex glass-covered magnetic stirring bar. The beaker and spatula used in weighing and transferring the lead acetate compound to the carboy were rinsed with four $250 \mathrm{~mL}$ volumes of deionized water, with all rinses being added to the carboy. After the lead acetate was completely dissolved, the $\mathrm{pH}$ of the solution was adjusted to a value of 4.5 by adding glacial acetic acid. The volume of acid used was recorded and subtracted from the volume of deionized water needed to bring the volume in the carboy to 20.0 liters.

After $\mathrm{pH}$ and total volume adjustments, the lead acetate solution was stirred for 2 to 4 hours per day for the next 3 to 4 days.

The concentration of lead in the nominal $20,000 \mathrm{ppm}$ solution was determined by FAAS. The analytical instrument used was a Perkin-Elmer model 2380 atomic absorption spectrophotometer fitted with a standard burner assembly consisting of a molded plastic mixing chamber, stainless steel nebulizer and a $10 \mathrm{~cm}$, single slot, titanium burner head (Perkin-Elmer Corp., Instrument Division, Norwalk, CT). An air-acetylene flame was used with a fuel flow of 2 liters per minute and an oxidizer flow of 16 liters per minute. A lead hollow cathode lamp operated at 10 milliamps provided the $283.3 \mathrm{~nm}$ absorbance line used for the lead determinations.

To evaluate the accuracy of lead concentration in the freshly prepared 20,000 ppm solution, a one step volumetric dilution was performed, resulting in a sample with a final lead concentration of approximately eight parts per million. Four to eight replicate samples of the concentrated solution were prepared for FAAS determination of lead concentration. Accuracy of the lead concentration to within $5 \%$ of the $20,000 \mathrm{ppm}$ target concentration was considered acceptable.

The FAAS instrument was calibrated using five lead concentrations well within the $20 \mathrm{ppm}$ linear working range of the instrument. Calibration concentrations were $4,6,8,10$, and $12 \mathrm{ppm}$, with each concentration being determined 16 times. The five calibration solutions were typically determined before and after the concentrated solution samples, with the data from both calibrations being combined in a single linear regression calculation. Calibration solutions were freshly prepared just prior to each instrument calibration by

\footnotetext{
${ }^{1}$ Certain suppliers of chemicals and equipment are identified by name in order to specify the experimental conditions adequately. This does not imply endorsement or recommendation by the National Institute of Standards and Technology nor does it imply that the particular brands of chemicals and equipment named are necessarily the best for the purpose.
} 
volumetric dilution of a commercial atomic absorption standard solution containing lead at 1,000 ppm (Fluka Chemical Corp., Ronkonkoma, NY).

Additional lead determinations of the 20,000 ppm solution were made periodically over the two to eight months that the concentration solution was being consumed. These determinations are listed in Table 1 . From one 20liter batch of concentrated lead solution, approximately 15 bottles each of 50,250 and $1,000 \mathrm{~mL}$ volumes could be dispensed. The actual volumes dispensed and the dates bottles were filled are listed in Table 2 .

\subsection{Dosing Solution Preparation}

The concentrated lead solution was dispensed by weight into polycarbonate containers of 50,250 and $1,000 \mathrm{~mL}$ volumes at NIST and shipped by courier to the University of Maryland at Baltimore (UMAB) for use by their personnel in preparing drinking water solutions for the experimental animals. The concentrated lead solutions in the above volumes were diluted into 20-liter carboys containing deionized water to provide final lead concentrations of 50 , 250 and $1,000 \mathrm{ppm}$. Although the $20,000 \mathrm{ppm}$ concentrated lead solution was adjusted to $\mathrm{pH} 4.5$, the acidity of the 50,250 and $1,000 \mathrm{~mL}$ volumes was insufficient to bring the $\mathrm{pH}$ of the 20 liter drinking water solutions to $\mathrm{pH}$ 4.5. Additional glacial acetic acid was added to each bottle of concentrated lead solution so that upon dilution, the 20 liter volumes of solution would have a $\mathrm{pH}$ of 4.5 . The amount of additional acid needed was determined empirically by dilution of one each of the 50, 250, and 1,000 mL volumes of concentrated solution to 20 liter volumes and adding glacial acetic acid to the 20 liter volume until $\mathrm{pH} 4.5$ was reached. The dilute drinking water solutions were prepared from the concentrated lead solutions by the attached dilution procedures (Appendix).

The first carboy of $20,000 \mathrm{ppm}$ lead acetate solution was prepared on the $18 \mathrm{th}$ of March, 1991. The solution was adjusted to $\mathrm{pH} 4.5$ with glacial acetic acid. The concentrated solution was transferred into 1,000, 250 and $50 \mathrm{~mL}$ bottles on March 27, 1991, with additional glacial acetic acid being added to each bottle. Fifteen bottles each of the $1,000,250$ and $50 \mathrm{~mL}$ volumes were filled.

One bottle of each volume was used at NIST to prepare the initial 20 liter carboys of drinking water at nominal concentrations of $1,000,250$ and $50 \mathrm{ppm}$. The carboys of dilute lead solution and the remaining 14 bottles each of concentrated lead solution were delivered to UMAB on September 27, 1991. Determinations of the lead concentration in the concentrated carboy solutions were made periodically by FAAS as the solutions were consumed. These analyses are summarized in Table 1.

Additional carboys of $20,000 \mathrm{ppm}$ lead acetate solution were prepared on January 6, 1992, March 19, 1992, and October 2, 1992. The March 19, 1992 preparation, and all subsequent ones, were mixed using a pyrex glass covered magnetic stirring bar. Earlier preparations had been stirred with a teflon covered stirring bar. The teflon covered stirring bar always shed wear particles into the solution and its use was therefore discontinued. The concentrated lead solutions were dispensed into 50,250 , and 1,000 $\mathrm{mL}$ bottles for delivery to UMAB as shown in Table 2. 


\subsection{Solution Monitoring by Flame Atomic Absorption Spectrophotometry}

Following dilution of the concentrated lead solution $(20,000 \mathrm{ppm})$ at UMAB to drinking water concentration levels, samples of the 50,250 and 1,000 ppm solutions were taken from the 20 liter carboys and shipped to NIST in polycarbonate containers for FAAS determination of the lead concentration. Samples were also taken from blank control carboys and from water bottles in use in animal cages. Lead concentration in the samples was typically determined within two to six days of receipt of the samples at NIST; however, in some instances, FAAS analyses were completed approximately two weeks after receipt of the samples.

The FAAS instrument was calibrated for drinking water solution monitoring at 4, 6, 8, 10 and $12 \mathrm{ppm}$ concentrations of lead. Drinking water samples were diluted to contain approximately $8 \mathrm{ppm}$ of lead. Each drinking water sample dilution was prepared in duplicate. Each duplicate sample dilution was determined by FAAS 16 times. The lead concentration of the samples was calculated by entering their FAAS absorbance values into the linear regression equation generated by determination of the calibration solutions. The resulting concentration values were averaged and reported with a standard deviation.

\subsection{DISCUSSION}

\subsection{Solutions of Lead Acetate}

The volume of data accumulated during the course of this experiment was quite large. As of April, 1993, lead concentration determinations had been made for 52 carboys of $50 \mathrm{ppm}$ concentration, 47 carboys of $250 \mathrm{ppm}$ concentration and 42 carboys of 1,000 ppm concentration. In addition, lead determinations had been made for various solutions taken from drinking water bottles in use by the experimental animals; 19 samples of $50 \mathrm{ppm}$ solutions, 15 samples of $250 \mathrm{ppm}$ solutions and 8 samples of $1,000 \mathrm{ppm}$ solutions.

Typically, samples were withdrawn from the carboys after approximately 48 hours of mixing following addition of the concentrated lead solution to the carboy. Samples were stored at room temperature until FAAS determinations were performed.

The 20 liter carboys used for dilution of the concentrated 20,000 ppm lead solutions to drinking water concentrations of 50,250 and $1000 \mathrm{ppm}$ were filled for the first time at NIST. Determination of the lead concentration, by FAAS, in the dilute solutions 30 days after the addition of the concentrated lead solution to the carboys gave the following values: 
Nominal Lead
Concentration

\section{ren}

50 ppm

$250 \mathrm{ppm}$

1000 ppm
FAAS Lead

Concentration

$\mathrm{Pb}, \mathrm{ppm} \quad$ Std Dev
\% Deviation from Target Concentration

$\begin{array}{lll}49.7 & 0.2 & -0.6 \\ 245 & 2.1 & -1.6 \\ 963 & 27 & -3.7\end{array}$

All subsequent lead solution data for 50, 250 and $1000 \mathrm{ppm}$ concentrations are from carboy solutions that were prepared at UMAB from concentrated 20,000 ppm solutions supplied by NIST.

The four carboys of concentrated lead acetate solution (nominally 20,000 ppm) prepared during the course of this study had their lead concentrations determined by FAAS numerous times, as listed in Table 1. An analysis of variance on the lead concentration values for the carboys revealed no statistically significant differences between the concentrations in the four carboys. Additionally, there was no significant drift in the concentration over time. A plot of the concentration determinations, subdivided by vertical lines to indicate the four individual $20,000 \mathrm{ppm}$ solution preparations, is shown in Figure 1.

The average lead concentration in the nominally $50 \mathrm{ppm}$ carboys was $51.4 \mathrm{ppm}$. However, there were statistically significant differences between the lead concentrations delivered, which depended upon the concentrated lead solution from which the dilute lead solution was prepared. The averages in the separate preparations ranged from a low of $49.6 \mathrm{ppm}$ to a high of $52.7 \mathrm{ppm}$. All except the highest of these falls within 5 percent of the 50 ppm target concentration and the highest is not significantly more than 5 percent above the target concentration. A plot of the concentration determinations, in chronological order and subdivided by dispensation date of the concentrated $20,000 \mathrm{ppm}$ solutions, is presented in Figure 2.

In the nominally 250 ppm carboys, the average lead concentration was 254.9 ppm. There were also statistically significant differences between the delivered lead concentrations depending on which 20,000 ppm concentrate preparation was used for dilution. The range of delivered values was from 251.76 to $260.8 \mathrm{ppm}$, all of which fall within 5 percent of the target concentration of $250 \mathrm{ppm}$. A plot of the concentration determinations, in chronological order and subdivided by dispensation date of the concentrated $20,000 \mathrm{ppm}$ solutions, is presented in Figure 3.

The average lead concentration in the nominally 1000 ppm carboys was 998 ppm. However, there were statistically significant differences between the delivered lead concentrations depending on when the 20,000 ppm concentrate was dispensed. The delivered concentration averages ranged from 972 to $1039 \mathrm{ppm}$, all within 5 percent of the targeted $1000 \mathrm{ppm}$ concentration. A plot of the 
concentration determinations, in time sequence and divided by dispensation date of the concentrated $20,000 \mathrm{ppm}$ solutions, is presented in Figure 4 . A composite plot of the 50, 250 and $1000 \mathrm{ppm}$ carboy concentrations presented along a continuous concentration axis is shown in Figure 5. A summary of the above statistical discussion of carboy concentrations is presented in Table 3 .

\subsection{Rat Drinking Water Bottle Solutions of Lead Acetate}

Monitoring of the lead concentration in the water bottles in use in the animal cages revealed a problem with lead concentration stability. Some weeks into the study, lead concentration values in the animal drinking water bottles were found to be significantly lower than that of the carboys they were being filled from. Close examination of the drinking water bottles revealed a biological contamination, possibly fungal, growing in the water bottles. A non-quantitative measurement (i.e., lead concentration not adjusted to dry weight of the biological material) of the lead concentration of the biological material revealed a concentration of several hundred ppm lead in a sample removed from a $50 \mathrm{ppm}$ solution. Apparently, the biological entity was accumulating and concentrating lead from solution in its tissue. UMAB personnel, alerted to this problem, reviewed their water bottle cleaning procedure and realized a bleach treatment step had been eliminated from the washing procedure. When the bleach treatment was reinstated, the biological contamination ceased to be a problem and lead concentrations in the drinking water bottles remained stable. The average lead concentration in the nineteen $50 \mathrm{ppm}$ drinking water bottles sampled, excluding the 6 bottles with concentrations affected by biological contamination, was $50.3 \mathrm{ppm}$, with a standard deviation of $2.4 \mathrm{ppm}$.

The average lead concentration in the fifteen $250 \mathrm{ppm}$ drinking water bottles sampled, excluding the one bottle with concentration affected by biological contamination, was $257.1 \mathrm{ppm}$, with a standard deviation of $8.5 \mathrm{ppm}$.

The average lead concentration in the eight $1000 \mathrm{ppm}$ drinking water bottles sampled, excluding two bottles with concentration affected by biological contamination, was $1,035.9 \mathrm{ppm}$, with a standard deviation of $55.6 \mathrm{ppm}$.

The lead concentration data from the rat drinking water bottle samples is presented graphically in figures 6,7 and 8 , respectively for the 50, 250 and 1,000 ppm concentrations.

The graph of the $50 \mathrm{ppm}$ drinking water concentrations, by virtue of having the greatest number of samples spanning the time period, most dramatically illustrates the effect of biological contamination on the lead concentration of the drinking water; nevertheless, the effect of the contamination is also seen in the graphs of the 250 and $1000 \mathrm{ppm}$ concentrations. Once the biological contamination was eliminated, lead concentrations returned to the appropriate target levels. 


\subsection{Conclusions}

The solution stability studies conducted during the beginning stages of this project provided confidence that drinking water solutions containing lead acetate would not experience decreases in concentration during storage and consumption. The major challenge of this project was to provide consistent accuracy in delivering lead containing drinking water over approximately a two and one half year time period. This time span required that numerous solutions be prepared at irregular intervals, as dictated by water consumption by the experimental animals. Consequently, the solution preparation protocols needed to be easily repeatable and provide a highly accurate lead concentration in the final drinking water product. The protocols developed for the production, dispensing and dilution of concentrated lead acetate solutions (detailed in Appendix 1) worked successfully when initially tested. As the experiment progressed, the protocols proved to be very reliable for generating relatively large volumes of drinking water. By early April, 1993, a total. of 141 carboys or 2820 liters of lead containing drinking water had been prepared.

When the average lead concentrations of the carboys were examined by subdividing them into groups based on the date that the 20,000 ppm lead concentrate was dispensed, all concentration averages fall within 5 percent of the target concentration values, with the exception of one data set for $50 \mathrm{ppm}$ carboys prepared from concentrate dispensed on August 18, 1992. The data sets for the 50, 250 and $1000 \mathrm{ppm}$ carboys describe what is statistically termed a normal data distribution around an average value, with 65 to 71 percent of the concentrations within one standard deviation of the average values and 89 to 98 percent within two standard deviations of the average values.

For the 1000 and $250 \mathrm{ppm}$ carboy solutions, the average solution concentration values all fall within 5 percent of the target values. For the $50 \mathrm{ppm}$ carboy solutions, all average concentration values fall within 5 percent of the target concentration with the exception of carboys prepared from 20,000 ppm concentrate dispensed on August 18, 1992. The average lead concentration in carboys prepared from the $20,000 \mathrm{ppm}$ concentrate dispensed on August 18 was $52.7 \mathrm{ppm}, 5.4$ percent above the $50 \mathrm{ppm}$ target concentration. This is the only set of data that does not achieve the goal of 5 percent or better accuracy in meeting target concentrations. However, this average value of $52.7 \mathrm{ppm}$, statistically, is not significantly higher than $52.5 \mathrm{ppm}$, the upper value of the plus or minus 5 percent range of acceptable 50 ppm concentrations, i.e., concentrations ranging between 47.5 and $52.5 \mathrm{ppm}$ are acceptable as $50 \mathrm{ppm}$ solutions.

The loss of lead from solution seen during the period of biological contamination in the drinking water bottles reinforced the need for on-going lead concentration monitoring. Had FAAS monitoring stopped after the initial analyses found no problems in meeting the desired concentrations in the first few carboy and drinking water solutions examined, the loss of lead from solution in the biologically contaminated drinking water bottles would never have been discovered. 


\subsection{References}

1. Jewett, K.L., Blair, W.R., Brinckman, F.E., Wang, F.W., "Stability of Aqueous Inorganic Lead Solutions in Polycarbonate Containers", NISTIR 4725, National Institute of Standards and Technology, 1991.

2. Blair, W.R., Olson, G.J., Brinckman, F.E., Paule, R.C,

"An International Butyltin Measurement Methods Intercomparison: Sample Preparation and Results of Analyses", NBSIR 86-3321, National Bureau of Standards, 1986.

\subsection{Acknowledgements}

This work was supported by the University of Maryland at Baltimore through Subcontract BS 73566-B. 


\section{Figure Captions}

Figure 1 Solution lead levels determined by FAAS for concentrated 20,000 ppm lead acetate solutions. Concentration determinations were made soon after initial solution preparation and subsequently as the solution was dispensed and consumed. Verticle lines subdivide the data into four groups based on preparation dates of the 20,000 ppm solutions. Horizontal dashed line indicates the target lead concentrations.

Figures 2, $3 \& 4$

The graphs show, respectively, the concentration values determined by FAAS for 50,250 and 1000 ppm carboy solutions of lead acetate. Verticle lines subdivide the data into groups based on the date of preparation and dispensation of the 20,000 ppm concentrated lead solution. The dashed horizontal lines show the nominal target concentration of the carboy solutions and the upper and lower limits of the \pm 5 percent range for solution accuracy.

Figure 5 Plot of the lead concentrations of all 50, 250 and $1000 \mathrm{ppm}$ carboys plotted on a common concentration axis.

Figures $6,7, \& 8$

Graphs show, respectively, the lead concentrations of 50,250 and $1000 \mathrm{ppm}$ drinking water solutions taken from water bottles in cages of the experimental animals. The loss of solution lead concentration due to water bottle contamination by biological growth, reaching a maximum effect at about 200 days into the study, is clearly seen. 


\section{APPENDIX \\ DILUTION INSTRUCTIONS for \\ LEAD ACETATE DRINKING WATER SOLUTIONS}

General Information and Instructions:

Use clean graduate cylinders for all volumetric measurements. Cylinders of 1000 or $2000 \mathrm{~mL}$ volumes are suggested.

After a soap and water wash and rinse, further clean graduate cylinders by allowing them to stand overnight full of 5\% aqueous nitric acid. Rinse 4 to 5 times with distilled water. Keep the tops of the cylinders covered when they are not in use.

Carboys of 20 liter capacity will be used to contain lead acetate drinking water solutions. Individual carboys will be filled with lead acetate solutions at 50, 250 and $1000 \mathrm{ppm}$ concentrations at NIST prior to their use at UMAB. The initial contact with lead acetate solutions will minimize any loss of solution concentration due to container wall adsorption. Do not wash the carboys before making dilutions of the concentrated lead solutions by the procedures described in the accompanying instructions.

The concentrated lead solutions have been $\mathrm{pH}$ adjusted at NIST to result in a $\mathrm{pH}$ of 4.5 in the diluted lead solutions.

All empty polycarbonate bottles should be returned to NIST for reuse. 


\section{DILUTION INSTRUCTIONS \\ for \\ LEAD ACETATE DRINKING WATER SOLUTIONS \\ 50 ppm Concentration}

1) Fill 20 liter carboy with 15 liters of distilled water.

2) Pour the contents of a $50 \mathrm{~mL}$ bottle containing concentrated lead solution into the carboy.

3) Add $25 \mathrm{~mL}$ of distilled water to the $50 \mathrm{~mL}$ bottle, put on the cap and shake the bottle. Pour this rinse water into the 20 liter carboy. Repeat this rinsing operation four times using $25 \mathrm{~mL}$ of distilled water for each rinse and add the rinse water to the carboy each time.

4) The carboy now contains: 15 liters of distilled water $50 \mathrm{~mL}$ of conc. lead solution $100 \mathrm{~mL}$ of rinse water

Volume in Carboy: $\quad 15.15$ liters

5) Add 4 liters plus $850 \mathrm{~mL}$ of distilled water to bring the final carboy volume to 20 liters.

6) After through mixing, the solution is ready for use. 


\section{DILUTION INSTRUCTIONS \\ for \\ LEAD ACETATE DRINKING WATER SOLUTIONS \\ 250 ppm Concentration}

1) Fill 20 liter carboy with 15 liters of distilled water.

2) Pour the contents of a $250 \mathrm{~mL}$ bottle containing concentrated lead solution into the carboy.

3) Add $125 \mathrm{~mL}$ of distilled water to the $250 \mathrm{~mL}$ bottle, put on the cap and shake the bottle. Pour this rinse water into the carboy. Repeat this rinsing operation a total of four times using $125 \mathrm{~mL}$ of distilled water for each rinse and add the rinse water to the carboy each time.

4) The carboy now contains: 15 liters of distilled water $250 \mathrm{~mL}$ of conc. lead solution $500 \mathrm{~mL}$ of rinse water

Volume in Carboy: $\quad 15.75$ liters

5) Add 4 liters plus $250 \mathrm{~mL}$ of distilled water to bring the final carboy volume to 20 liters.

6) After through mixing, the solution is ready for use. 


\section{DILUTION INSTRUCTIONS \\ for \\ LEAD ACETATE DRINKING WATER SOLUTIONS \\ 1000 ppm Concentration}

1) Fill 20 liter carboy with 15 liters of distilled water.

2) Pour the contents of a one liter bottle containing concentrated lead solution into the carboy.

3) Add $250 \mathrm{~mL}$ of distilled water to the one liter bottle, put on the cap and shake the bottle. Pour this rinse water into the 20 liter carboy. Repeat this rinsing operation four times using $250 \mathrm{~mL}$ of distilled water for each rinse and add the rinse water to the carboy each time.

4) The carboy now contains: 15 liters of distilled water

1 liter conc. lead solution

1 liter of rinse water

Volume in Carboy: 17 liters

5) Add 3 liters of distilled water to bring final carboy volume to 20 liters.

6) After through mixing, the solution is ready for use. 
TABLE 1

Determination of Lead Concentration in 20,000 ppm Solutions

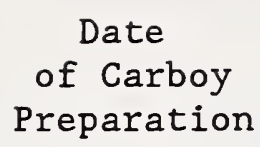

March 18, 1991

January 6, 1992

January 13, 1992

January 23, 1992

January 27, 1992

March 20, 1991

March 22, 1991

April 15, 1991

August 2, 1991

Date of

FAAS

Analysis

$\mathrm{Pb}$ Conc (ppm)

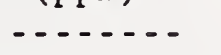

\section{9,146}

19,159

20,260

18,995

20,199

19,109

19,065

76
44
366

Number of Independent

Dev Dilutions

- . - .

1151

1185

847

130

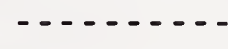

$\begin{array}{ll}2 & 10 \\ 2 & 20 \\ 5 & 38 \\ 3 & 96\end{array}$

10

20

96
Number of Replicate

Analyses
March 19, 1992
March 26, 1992

June 17, 1992

June 25, 1992

June 26, 1992

August 20, 1992

September 2, 1992
19,776

18,469

19,813

18,949

18,437

18,870

20,200

20,434
October 27, 199
April 14, 1993

November 10, 1992

April 14, 1993
401

202

492

127

509

193

587

118

March 18, 1991 Average Concentration 19,390 585

January 6, 1992 Average Concentration 19,458 642

March 19, 1992 Average Concentration 19,052 611

October 27, 1992 Average Concentration 20,317 166

Average of all 15 determinations: $19,392 \quad 663 \quad(\mathrm{RSD}=3.4 \%)$
96

96

96 
TABLE 2

Dispensing Dates and Volumes of 20,000 ppm Concentrated Lead Solutions

$\begin{array}{ccccc}\begin{array}{c}\text { Preparation } \\ \text { Date }\end{array} & \begin{array}{c}\text { Dispensing } \\ \text { Date }\end{array} & \begin{array}{c}50 \mathrm{~mL} \\ \text { Bottles }\end{array} & \begin{array}{c}250 \mathrm{~mL} \\ \text { Bottles }\end{array} & \begin{array}{c}1000 \mathrm{~mL} \\ \text { Bottles }\end{array} \\ 3 / 18 / 91 & 3 / 27 / 91 & 15 & 15 & 15 \\ & & & & \\ 1 / 6 / 92 & 1 / 21 / 92 & 12 & 8 & 8 \\ & 2 / 10 / 92 & 0 & 9 & 8 \\ 3 / 19 / 92 & 4 / 13 / 92 & 12 & 10 & 8 \\ & 8 / 18 / 92 & 12 & 12 & 8 \\ 10 / 27 / 92 & 12 / 18 / 92 & 8 & & 0 \\ & 2 / 02 / 93 & 0 & 0 & 0\end{array}$


TABLE 3

\section{SUMMARY of CARBOY DILUTIONS}

\begin{tabular}{cccc}
$\begin{array}{c}\text { Target } \\
\text { Concentration }\end{array}$ & $\begin{array}{c}\text { Number } \\
\text { Prepared }\end{array}$ & \multicolumn{2}{c}{$\begin{array}{c}\text { Average Lead } \\
\text { Concentration }\end{array}$} \\
$50 \mathrm{ppm}$ & 52 & 51.4 & 2.2 \\
& & & \\
$250 \mathrm{ppm}$ & 47 & 254.9 & 8.1 \\
$1000 \mathrm{ppm}$ & 42 & 998.2 & 31.1
\end{tabular}




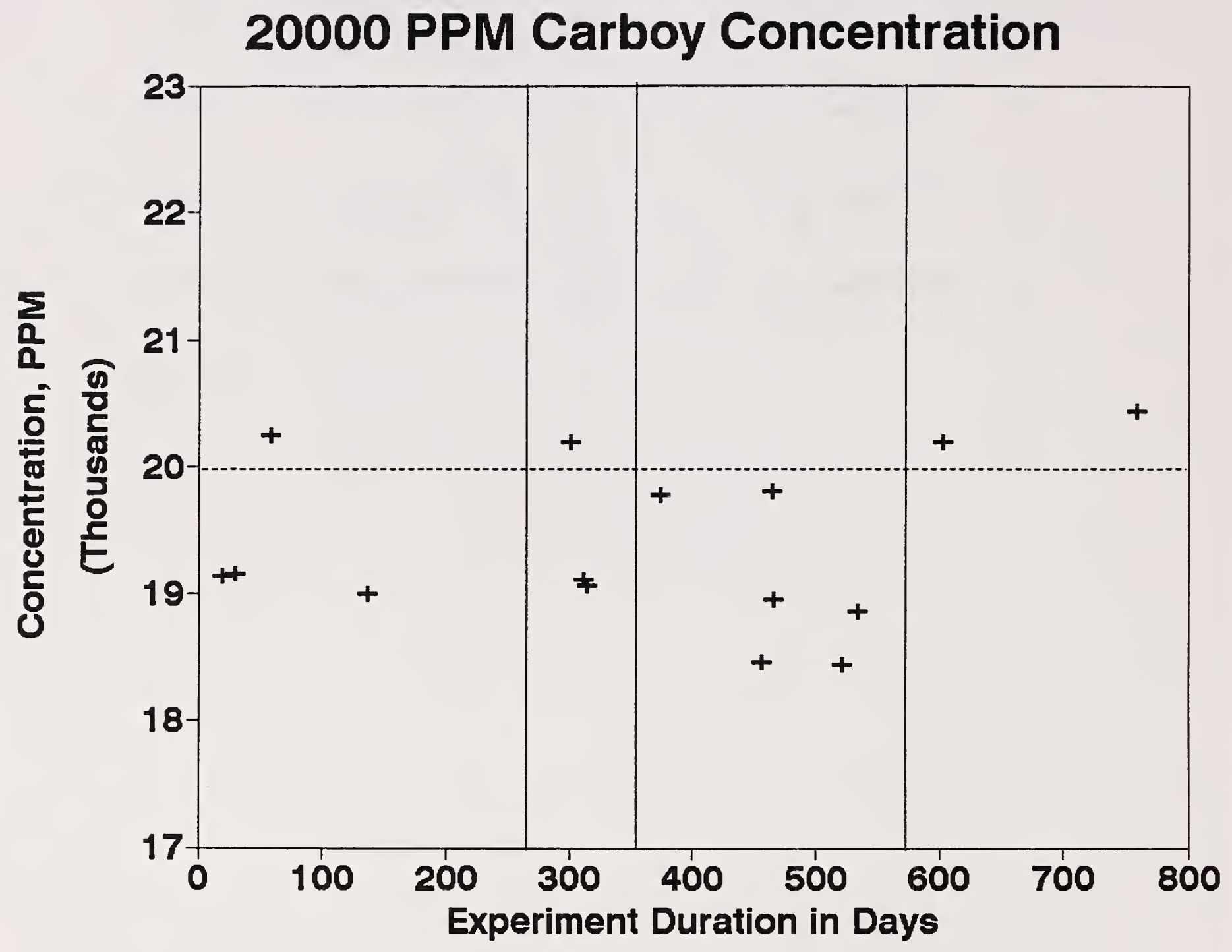




\section{PPM Carboy Concentrations}

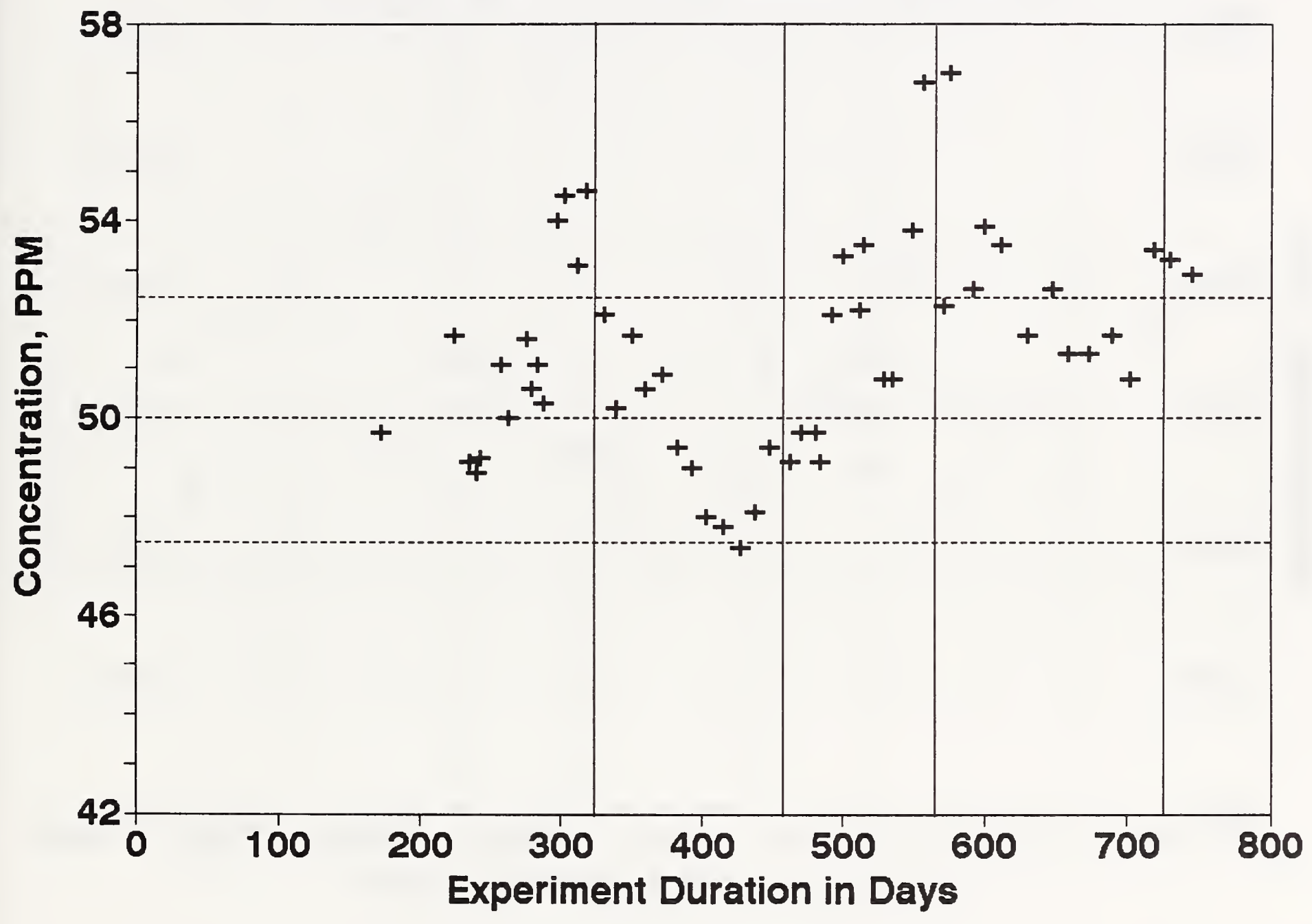


250 PPM Carboy Concentrations

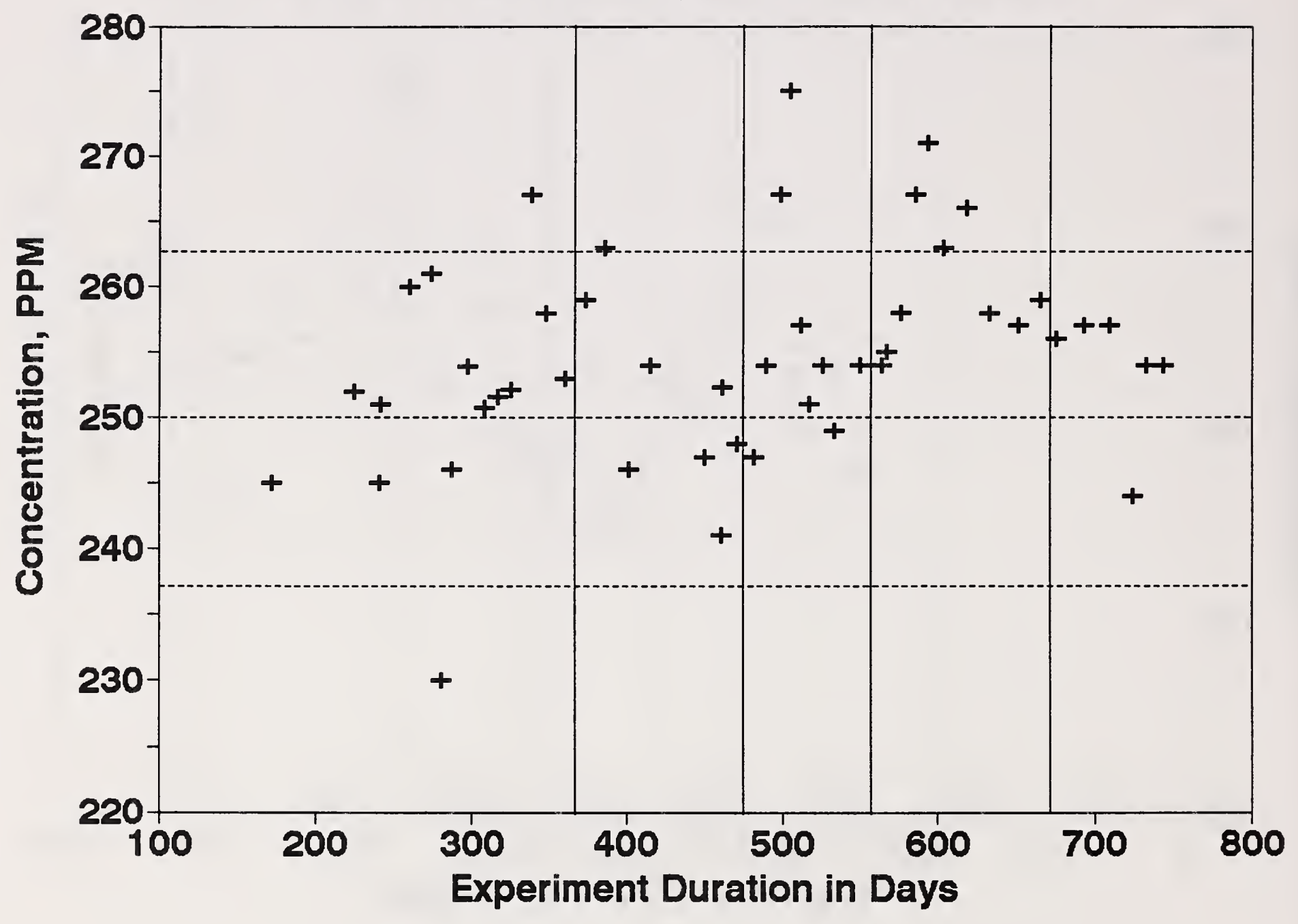




\section{PPM Carboy Concentrations}

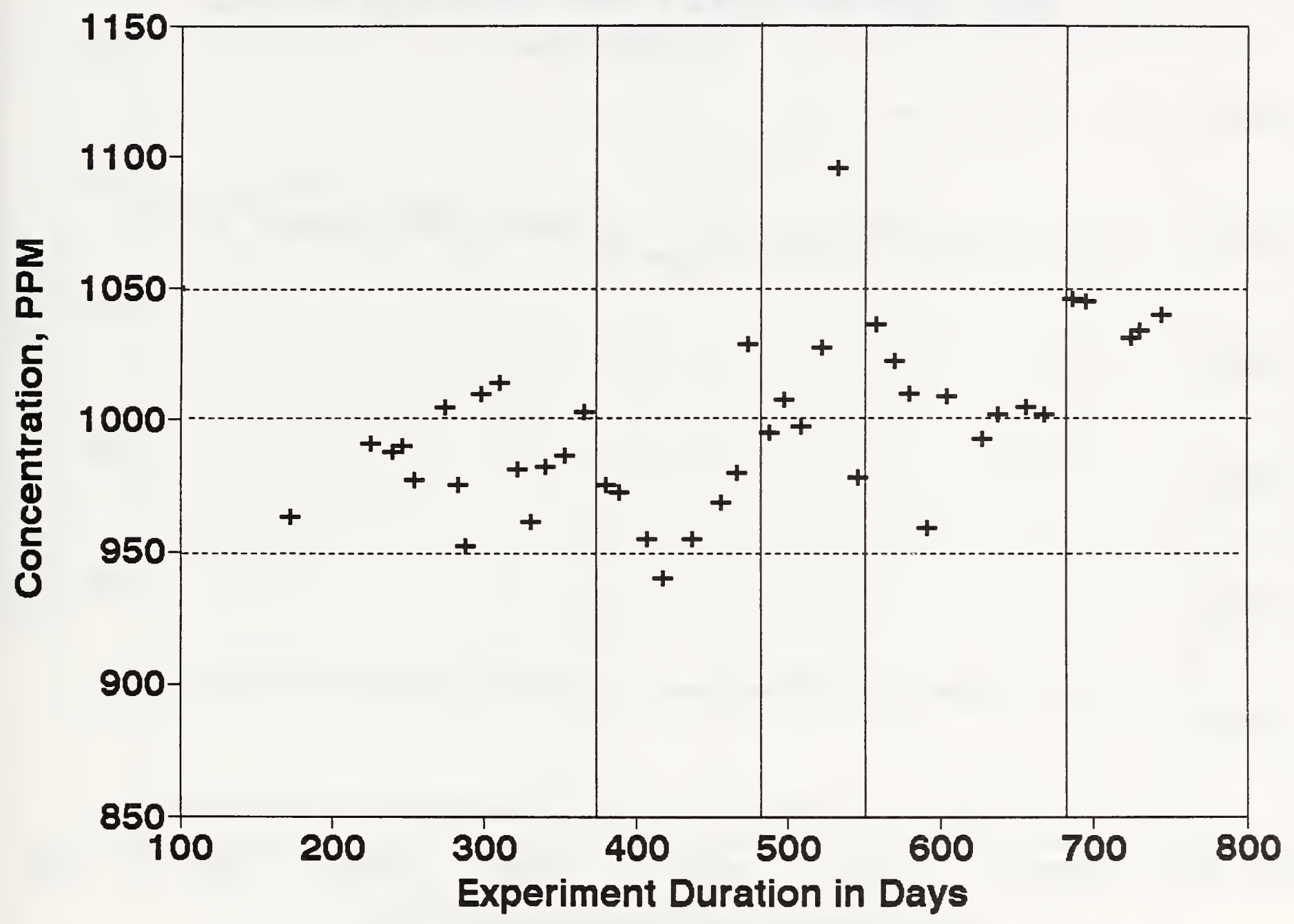




\section{0, $250 \& 1000$ PPM Carboy Conc.}

\section{All Dilutions}

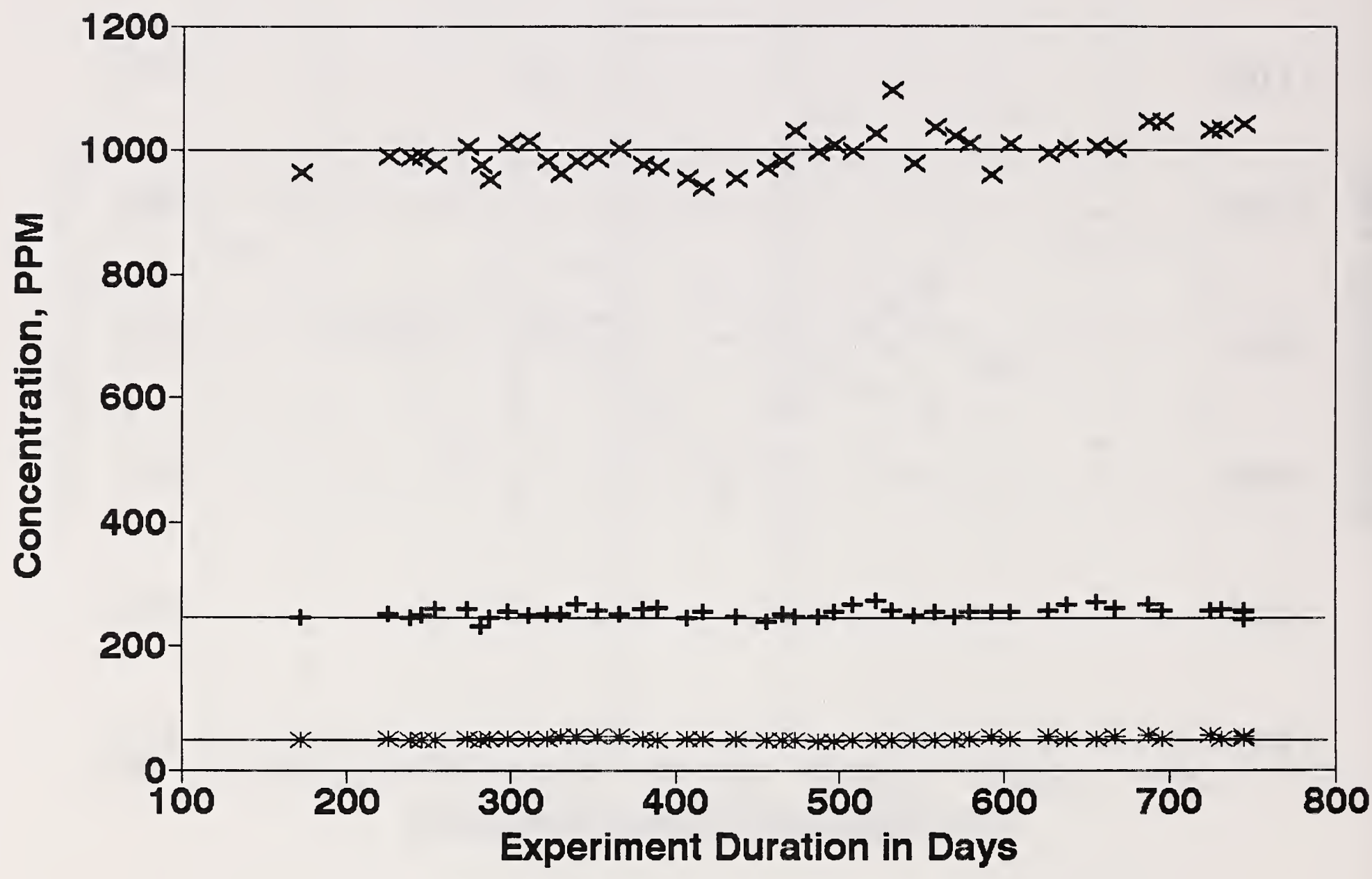


50 PPM Rat Drinking Water Bottles

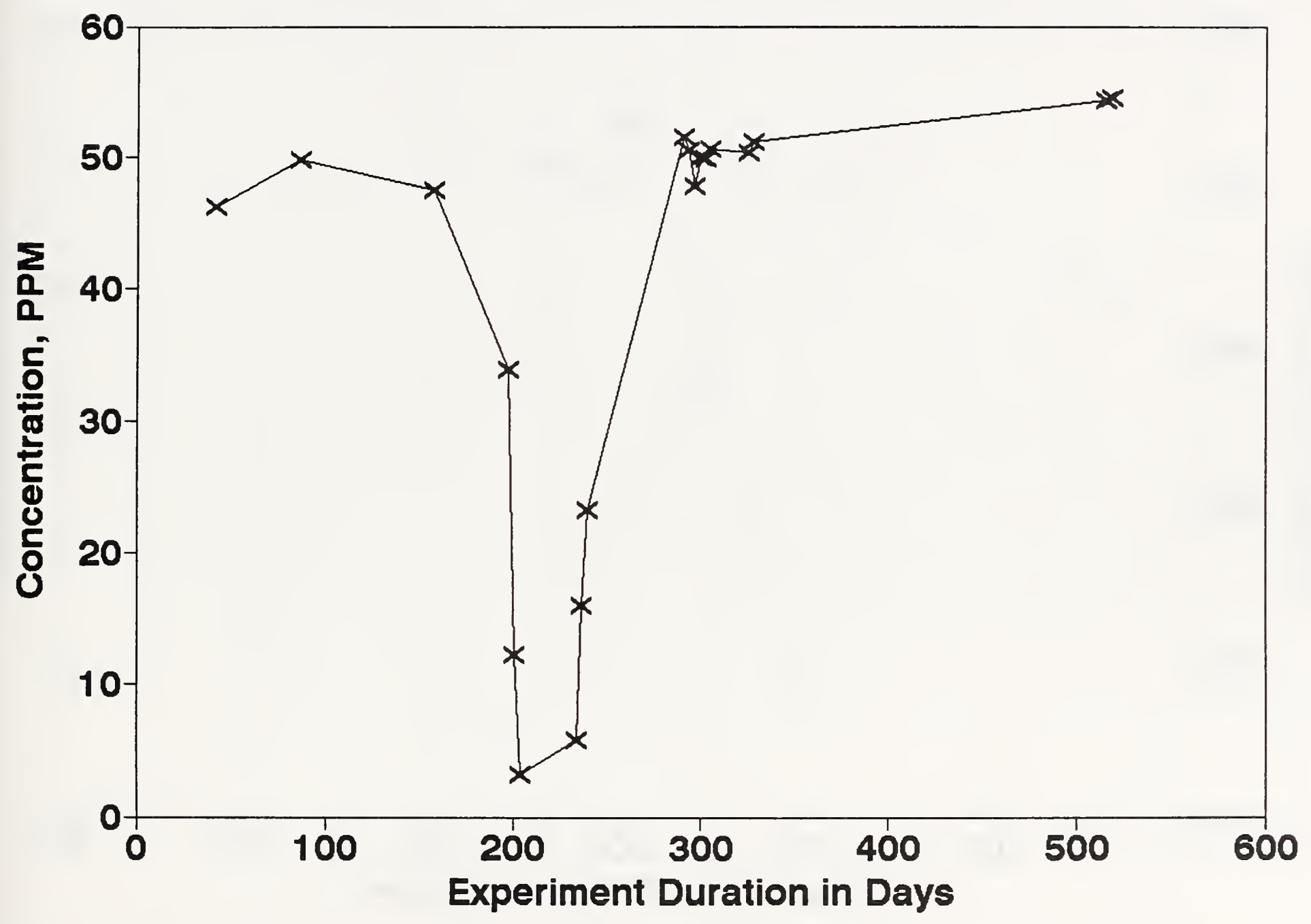




\section{PPM Rat Drinking Water Bottles}

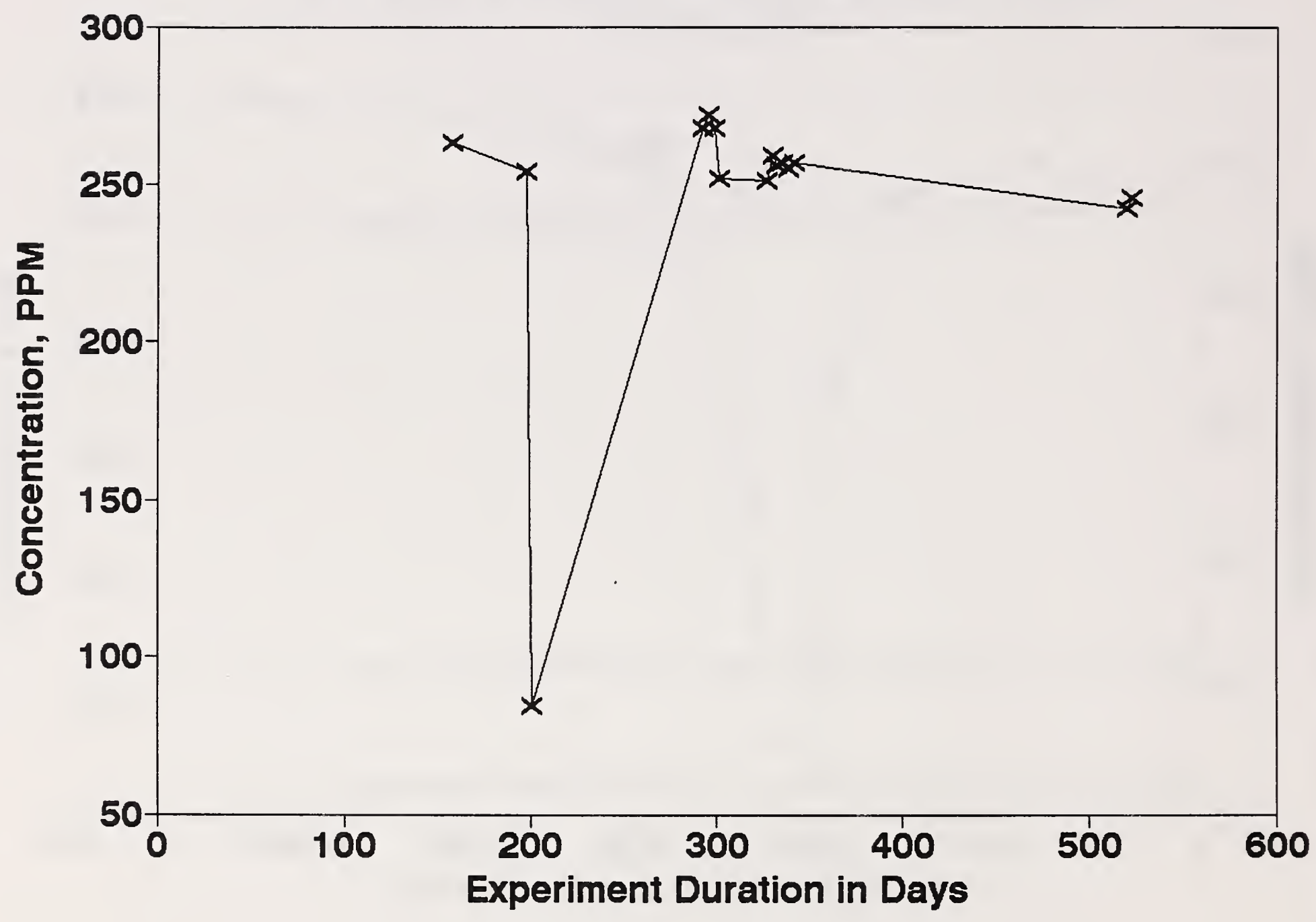




\section{PPM Rat Drinking Water Bottles}

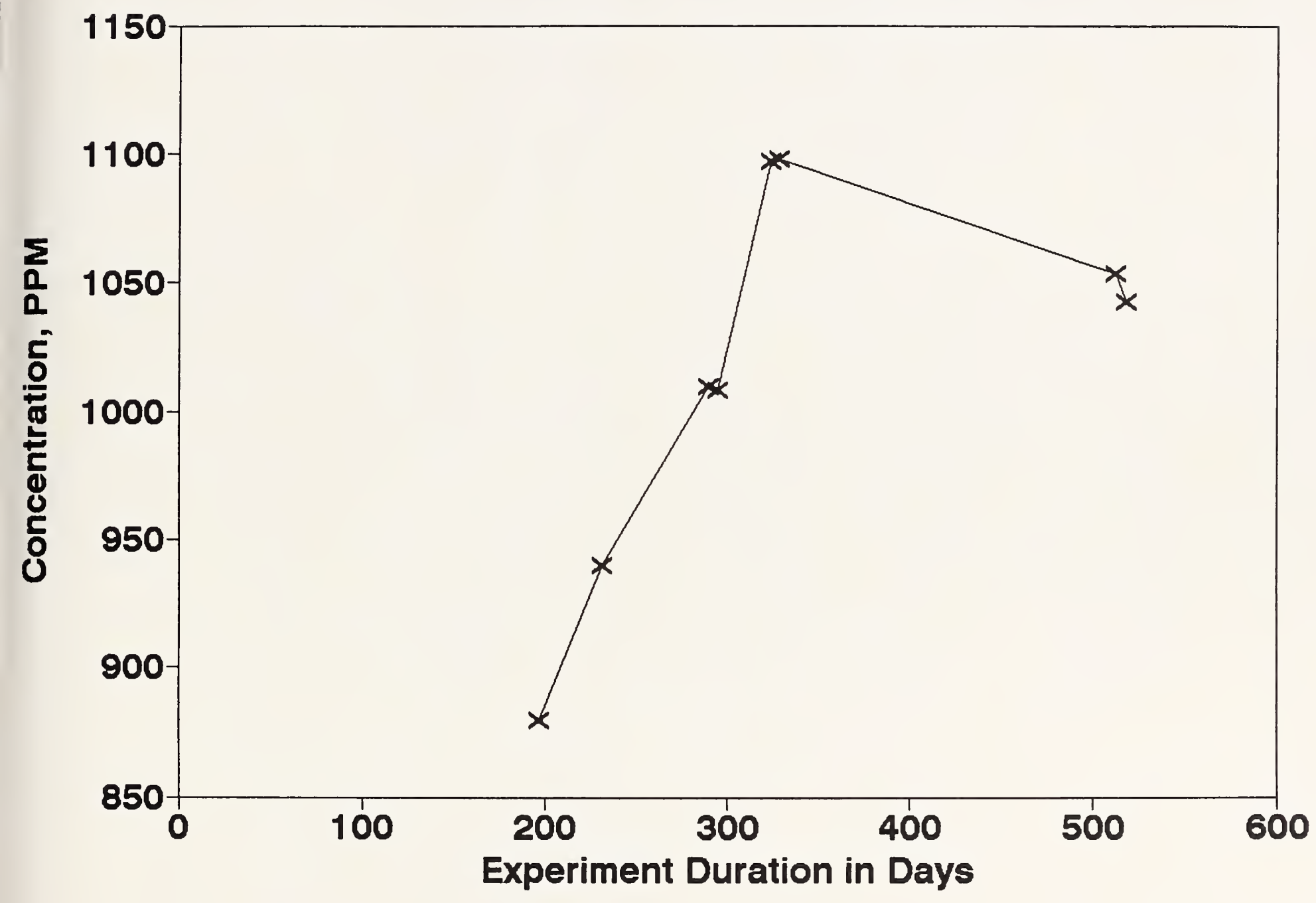




